\title{
CLINICAL AND PATHOLOGICAL OBSERVATIONS ON RELAPSE AFTER SUCCESSFUL LEUCOTOMY
}

\author{
BY \\ T. MCLARDY and D. L. DAVIES \\ From the Institute of Psychiatry, Maudsley Hospital, London
}

Return of mental symptoms after their disappearance or marked amelioration for a substantial period following bilateral frontal leucotomy has been described in a small proportion of cases by most psychiatrists who have published a detailed analysis of their postoperative clinical results. Nowhere in the literature, however, has the occurrence of relapse after recovery been correlated with the actual position and dimensions of the leucotomy lesions as established after death. The main purpose of the present paper is to describe the anatomical findings in the six most striking cases with a history of such a relapse out of the leucotomy brain material and case records being collected at the Maudsley Laboratory, and to discuss practical and theoretical implications of the findings in these cases and others in the literature in which the surgical damage can be reliably evaluated. Some clinical features of these and other relapsed cases in the literature of "psychosurgery" can conveniently be discussed at the same time.

\section{Material}

Summarized clinical histories of the six cases are given below, together with a description of the leucotomy cuts as found after fixation of the brains. The data most relevant to the discussion are further summarized in the Table. Details of premorbid personality and of body build were unfortunately lacking in most of the case records. The terms used in describing the position and extent of cuts are defined in Figs. 1 and 2.

\section{CASE $\dot{1}$}

Pre-operative History.-A.B. was an only child of parents of mentally healthy stock. His early development was normal. At school he was outstanding in art and sport. After three and a half years in various clerking jobs he volunteered for the R.A.F. at the age of 19 , became an air gunner, was awarded the D.F.M., and had completed fifteen operations at the time of his breakdown in 1943. He had had no previous illness except rheumatic fever at the age of 12 . His premorbid personality was described as intelligent, energetic, steady, reliable, and open; a good mixer, fond of sport andambitious in art; normally hetero-sexual. $\mathrm{He}$ was athletic in body build, with a strong masculine face.

In October, 1943 at the age of 23 he began to have feelings of inadequacy. He came to believe that he had an obviously weak chin and that people could see by his face that he was homosexual. He developed sniffing and snorting movements which distorted his facial appearance. After unsuccessful psychotherapy in a military psychiatric hospital he was boarded out of the R.A.F. in July, 1944 . He became rapidly more tense and agitated and later that same month underwent leucotomy. No detailed record of investigations before operation can be traced.

Leucotomy.-Subsequent laboratory investigation of the brain revealed the smooth-walled slit-like lesions to be practically symmetrical, unusually rostral, and limited to involvement of the dorsal segment of white matter on the left side and to the dorsal segment and an adjacent part of the central segment on the right side. Fig. 3 illustrates the position of the entry marks and the plane and extent of the cuts in relation to the frontal convolutions and Brodmann's areas.

Postoperative History.-Immediately after the operation he felt extremely well, his mannerisms ceased, and he was aware of heightened libido leading to increased sexual activity. His parents noted that he was more confident, more active, and more ambitious than before the illness. Assisted by a Government grant he took a two-year course in commercial art; but, failing to obtain work of that nature, he returned to clerical employment in September, 1947. He became gradually discouraged, and in February, 1948 broke off an engagement to marry. In March, 1948 all his previous symptoms began to return, and when he was readmitted to hospital in July, 1948 his condition was as bad as it had been before operation : he was sniffing and snorting ; unhappy, tense, impatient, and resentful ; talking rapidly and at great length of his delusions (such as one of reference to his homosexuality when, in Switzerland in July, 1948, he thought he heard a foreigner calling him "Herr Si-si") ; banging on the table to emphasize his points; and demanding another operation on his brain or else he would kill himself. His I.Q. was found 

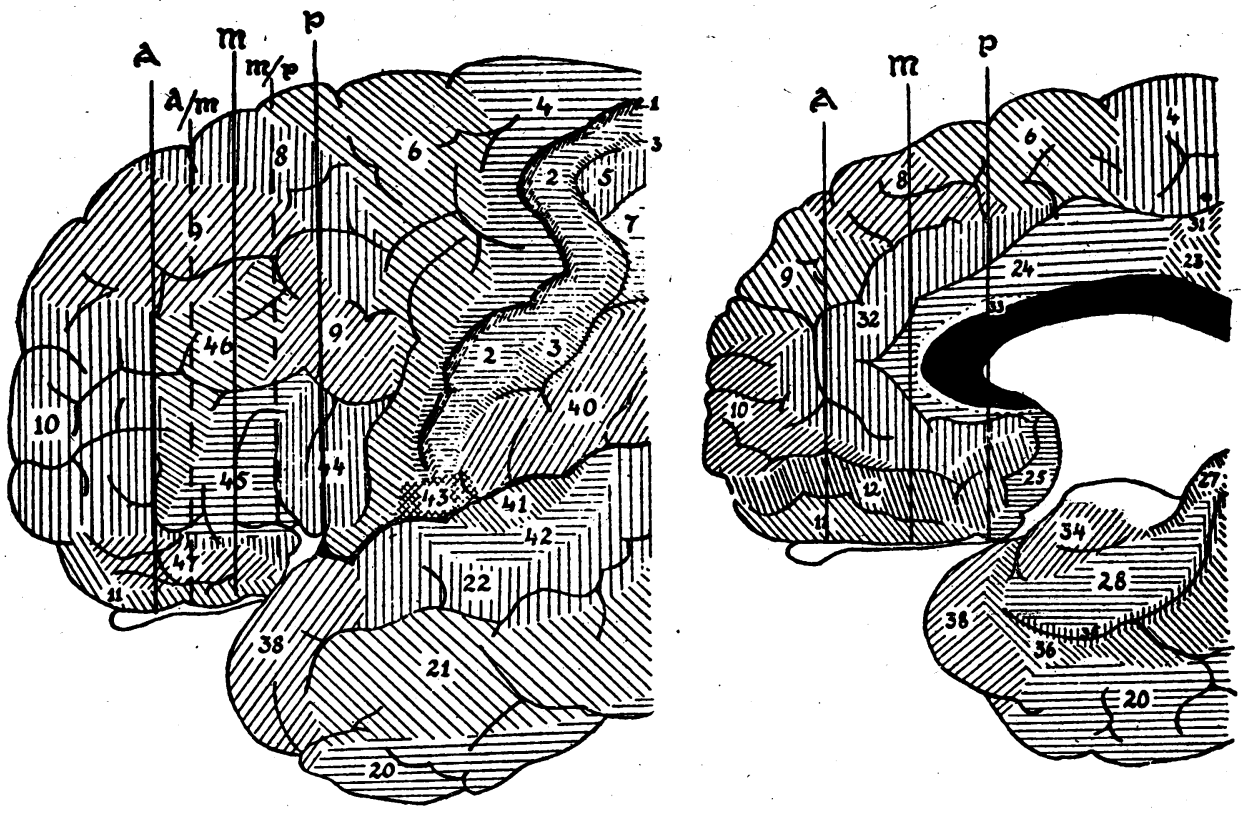

Fig. 1. " $M$ " denotes the plane perpendicular to the orbital plate and passing through the centre of "pars triangularis" (area 45), the usual leucotome entry point aimed at in this country. Planes $A$ and $P$ lie $1 \frac{1}{2} \mathrm{~cm}$. anterior and posterior respectively to $M, A / M$ and $M / P$ midway between. When the leucotomy lesion is cystic, curved, or oblique, its mean plane is utilized in summarized descriptions.

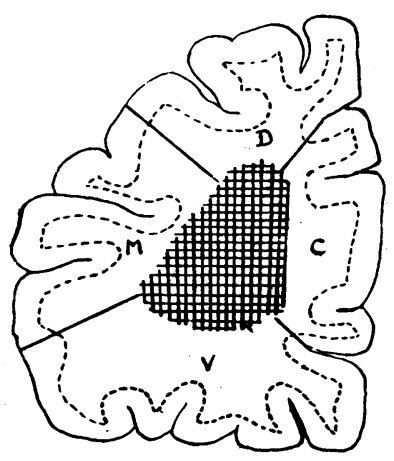

Fig. 2.-Five segments of white matter are differentiated in the coronal plane : $\mathrm{D}=$ dorsal ; $\mathbf{M}=$ middle ; $\mathbf{V}=$ ventral ; $\quad \mathbf{C}=$ cingulate ; Hatched = central. Involvement of a segment is recorded as positive when a majority of the fibres in it are cut.

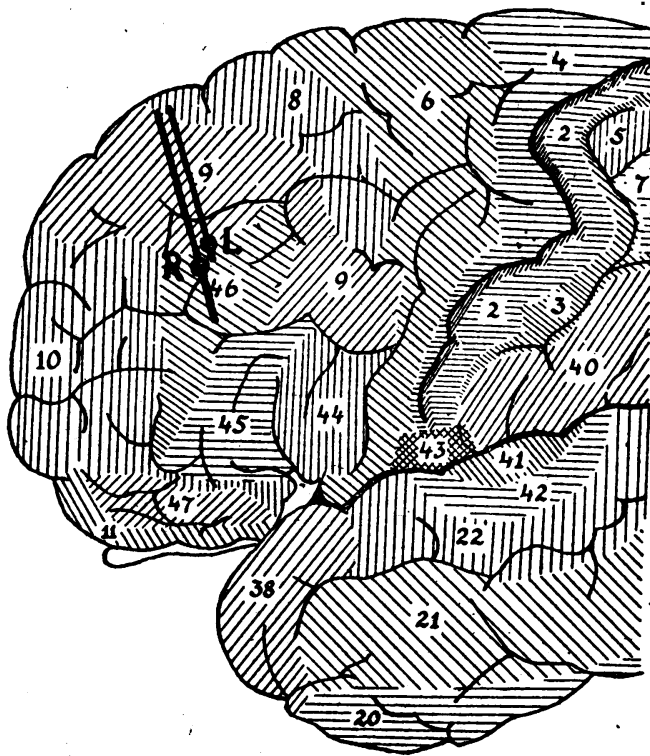

Fig. 3.-Case 1. 
to be 114 on the Matrix test and 127 on the Mill Hill Vocabulary. He was diagnosed as being in a mixed state with depressive and paranoid features.

His excitement settled rapidly in response to reassurance and conservative measures. He became cheerful, hopeful, and less insistent about his delusions. At occupational therapy he displayed creative artistic ability which seemed unimpaired in every respect when compared with his productions at art school and during his premorbid period. He began to make reasonable plans about his work and marriage. On Sept. 8, 1948, his fiancée was found to be pregnant. On Sept. 13 he quarrelled with his parents about the marriage. Next day he escaped from hospital, went home, and committed suicide by taking aspirin; this was four years and two months after the date of the leucotomy.

\section{CASE 2}

Pre-operative History.-B.C. was a married man who, at the age of 56, after being unusually quiet and thoughtful for five months, developed such severe depression and apathy of mood with delusions of poverty and ruin as to require hospitalization. He remained in this mental state for five years, physical therapy being precluded by complications following a surgical operation for retention of urine. He then received two electric convulsions and became much improved in mood. Because of symptoms of compression of a lumbar vertebra the projected course of treatment had, unfortunately, to be stopped, and he rapidly relapsed into his previous state.

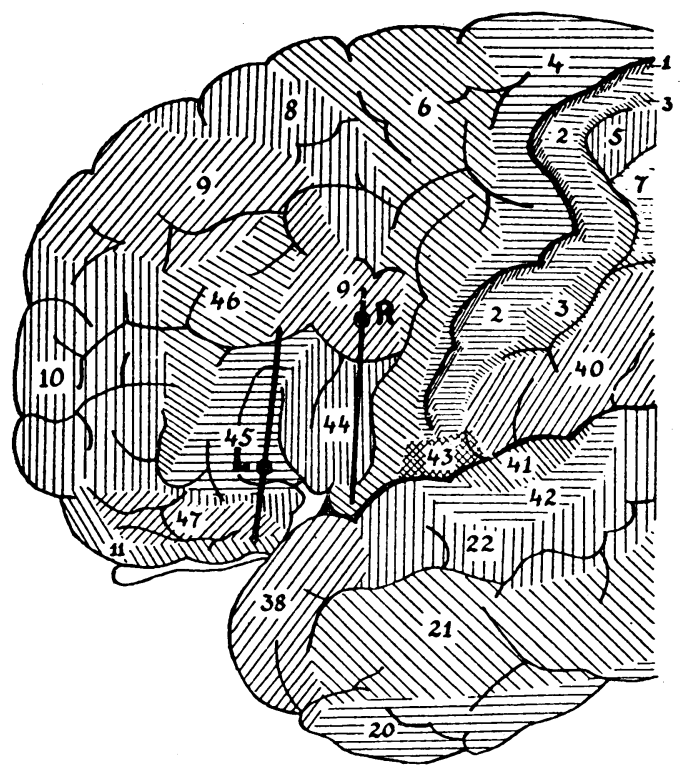

Fig. 4.-Case 2.

Leucotomy was performed five years and eight months after admission to hospital. Subsequent laboratory investigation of the brain revealed the left leucotomy scar to involve a major portion of the central, ventral, and cingulate segments of white matter in plane $\mathbf{M}$; the right scar involved a large proportion of the central, ventral, and middle segments in plane $P$ (Fig. 4).

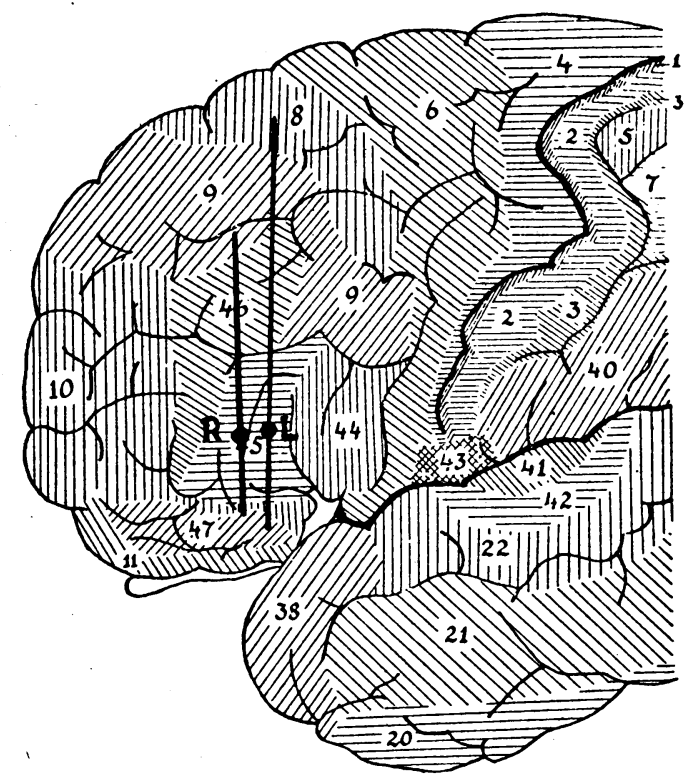

Fig. 5.-Case 3.

Postoperative History.-He made such rapid full recovery to his normal cheerfulness of mood and physical activity that he was discharged home three months after the date of operation. His recovery was fully maintained until one year and five months later, when he developed a severe carbuncle, relapsed completely to his pre-operative mental state, persuaded his doctor and wife not to let the hospital know of his condition, and committed suicide a month later, one year and nine months from the date of operation.

\section{CASE 3}

Pre-operative History.-C.D. was a youth of athletic physique who at the age of 19 after a homosexual incident developed mild paranoid schizophrenic symptoms whilst on overseas service, responded successfully to a course of cardiazol shock treatment, and returned to his duties as a private soldier for four years. Almost immediately after his discharge from the Army (on physical grounds) in August, 1944 he was observed to display delusions of reference and persecution, fears of insanity, and attacks of trembling. During the succeeding months he became tense, agitated, depressed, and acutely suspicious. Shock therapy was apparently not repeated.

Leucotomy was performed seven months after the onset of the acute recrudescence. Subsequent investigation of the fixed brain showed both cuts to lie in plane " M," the left one affecting all five segments of white 
matter, the right one sparing the dorsal and cingulate segments (Fig. 5).

Postoperative History.-After a postoperative hypomanic phase of three weeks' duration his mood returned to normal, his delusions faded, and he was discharged recovered at the end of two and a half months. In character hè altered for the worse, becoming completely irresponsible and untruthful, but he worked satisfactorily as a night porter for one year without evidence of delusions. He then gave up work through laziness, gradually relapsed into a state of moody abusive suspicion, and had to be re-certified. A year later, no improvement having occurred in response to psycho-

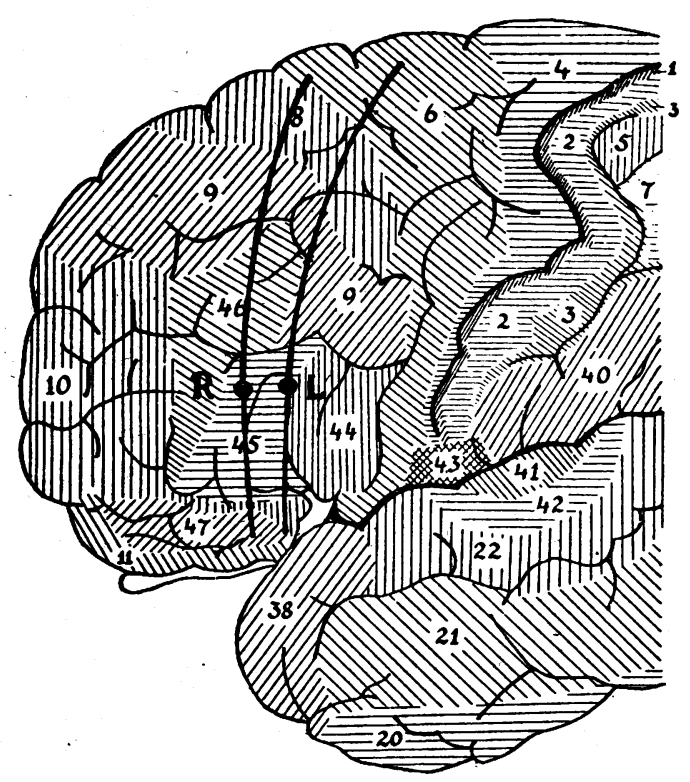

FIG. 6.-Case 4.

therapy, insulin coma treatment was started. His behaviour had become rather worse when, during the fifteenth treatment, coma became irreversible and he died, two and a half years from the date of operation.

\section{Case 4}

Pre-operative History.-D.E. was a very over-dependent hypochondriacally-inclined domestic maid who, at the age of 19 and without apparent cause, became depressed with delusions of reference and attempted suicide. She improved for about four months after a course of electric convulsions (E.C.T.), but two months later was described as sullen, suspicious, and impulsively aggressive, with auditory hallucinations. She now failed to respond to courses of E.C.T. and of continuous narcosis. A course 'of insulin coma rendered her quiet, amenable, and employable for one month. She then relapsed completely and remained resistive, restless, and violent in her behaviour without remission until operated upon eighteen months later.
Leucotomy was performed two years and ten month after the onset of illness. Subsequent investigatio revealed the symmetrically curved left and right lesion to involve all five segments of white matter at the levep of planes $M / P$ and $M$ respectively (Fig. 6). The only white matter entirely spared was that of the rectat gyri.

Postoperative History.-On recovery from the opera tion she was quiet and rational and remained so unt? discharged " recovered" at the end of two and a half. months. She resumed her previous occupation success: fully for two months, and then relapsed rapidly into hef pre-operative state. She now, however, responded $\mathbf{s}$ well to superficial psychotherapy that six months lates she was able to return home and to her work again for period of nine months. She was then jilted by a mad by whom she feared she was pregnant and relapseg rapidly into a more suspicious, impulsively violent, an€̣ destructive condition than ever before. Three month later she suffered a major epileptic fit, six months later a second one, and two months later a third one in whicto she died, two and a half years from the date of he? operation.

\section{CASE 5}

Pre-operative History.-E.F. was an asthenic nervou $\vec{N}$ overprotected young woman who at the age of $\frac{2}{2}$. developed fits of depression with obsessional ruminafof about religious topics and fear of suicide. In spitero intensive out-patient psycho-therapeutic and phys treatment throughout the following four years drex symptoms became gradually more severe. At the ent of that period an in-patient course of insulin shock fageff to produce change and a further course of E.C.T. $091 \%$ converted her mood from depression to hypomentia without modifying her obsessional rumination or ritualistic behaviour.

Leucotomy was performed four and a half years aftes the onset of the illness. Subsequent examination of the brain showed the major portion of all five segments of white matter in each hemisphere to be involved in the lesion, at plane $M$ (Fig. 7). Only the white matter of gyrus rectus on either side was wholly spared.

Postoperative History.-She suffered some permanen loss of spontaneity but showed a gradual improvement in her mental symptoms for four months. At the en of this period her obsessional ideas and actions were. much less vivid and absorbing than before and she was discharged home. About five months later she starte to regress gradually to her pre-operative condition Intensive psychotherapy produced no improvement, anf ultimately electro-narcosis was initiated. During the fourth treatment she suffered irreversible syncope an died, two years from the date of operation.

\section{CASE 6}

Pre-operative History.-F.G. was a young marrie woman who at the age of 30 rapidly developed a stato of seclusive negativistic mutism alternating with spells of agitation with delusions of reference and persecution Three years later her excited phases became very violenf⿰⿺𠃊一兀) 


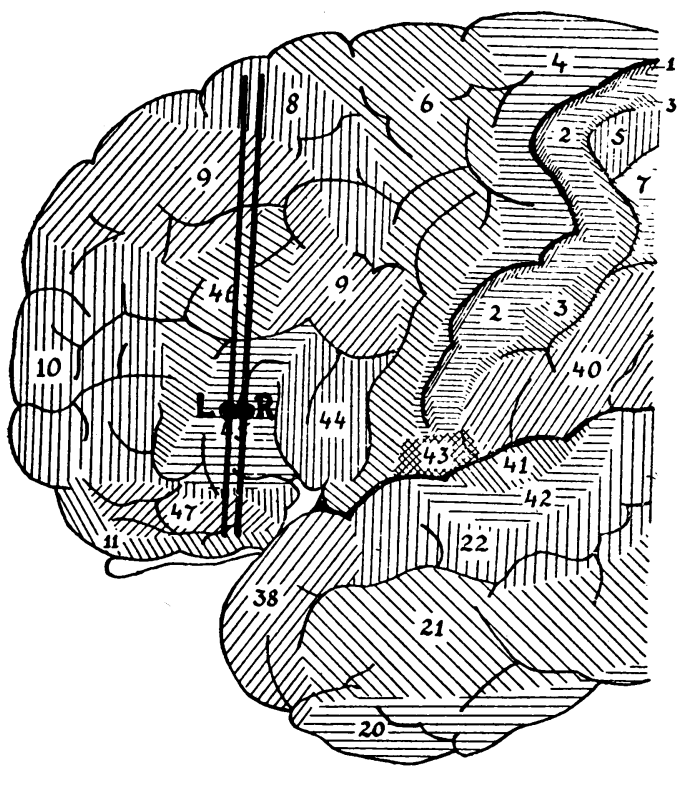

Fig. 7.-Case 5.

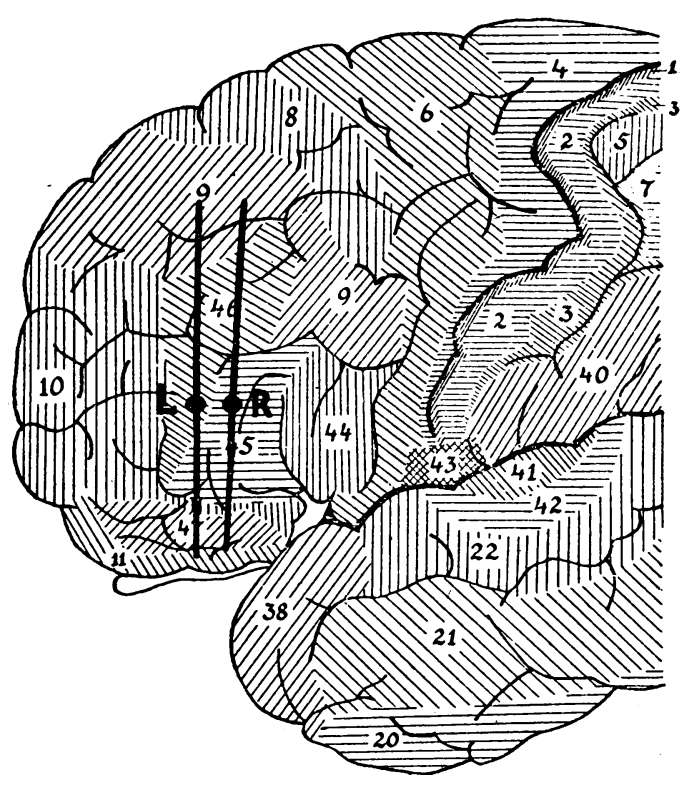

FIG. 8.-Case 6.

TABLE

SUMMARY OF DATA FROM CASES 1 TO 6

\begin{tabular}{|c|c|c|c|c|c|c|c|}
\hline $\begin{array}{l}\text { Case } \\
\text { No. }\end{array}$ & Main pre-operative symptoms & $\begin{array}{l}\text { Duration } \\
\text { of illness }\end{array}$ & $\begin{array}{r}\text { Plan } \\
\text { cu }\end{array}$ & $\begin{array}{l}\text { e of } \\
\text { ts }\end{array}$ & $\begin{array}{l}\text { Segments } \\
\text { cut } \\
\text { (out of } 10 \text { ) }\end{array}$ & $\begin{array}{l}\text { Duration of } \\
\text { recovery }\end{array}$ & $\begin{array}{l}\text { Environmental } \\
\text { factor in } \\
\text { relapse }\end{array}$ \\
\hline 1 & $\begin{array}{l}\text { Delusions of reference and } \\
\text { unworthiness; agitated depres- } \\
\text { sion ; facial tics }\end{array}$ & 9 mths. & $\underset{\mathrm{A} / \mathrm{M}}{\mathbf{M}}$ & $\underset{\mathbf{A} / \mathbf{M}}{\mathbf{R}}$ & 3 & 3 yrs. 8 mths. & + \\
\hline 2 & $\begin{array}{l}\text { Depression ; delusions of poverty } \\
\text { and sin }\end{array}$ & 5 yrs. 8 mths. & $\mathbf{M}$ & $\mathbf{P}$ & 6 & 1 yr. 8 mths. & + \\
\hline 3 & $\begin{array}{l}\text { Paranoid delusions; tenseness; } \\
\text { agitation }\end{array}$ & 7 mths. & $\mathbf{M}$ & $\mathbf{M}$ & 8 & 1 yr. 3 mths. & - \\
\hline 4 & $\begin{array}{l}\text { Paranoid delusions; auditory } \\
\text { hallucinations; violence }\end{array}$ & 2 yrs. $10 \mathrm{mths}$. & $\mathbf{M} / \mathbf{P}$ & $\mathbf{M}$ & 10 & $1 \mathrm{yr} .1 \mathrm{mth}$. & + \\
\hline 5 & $\begin{array}{l}\text { Obsessional rumination and } \\
\text { activity; depression }\end{array}$ & $4 \frac{1}{2}$ yrs. & $\mathbf{M}$ & $\mathbf{M}$ & 10 & 9 mths. & - \\
\hline 6 & $\begin{array}{l}\text { Catatonic phases of excitement } \\
\text { and stupor; no remissions }\end{array}$ & 15 yrs. & $\mathbf{A} / \mathbf{M}$ & $\mathbf{M}$ & 8 & $2 \frac{1}{2}$ mths. & - \\
\hline
\end{tabular}


and destructive and her negativistic phases more acute. She was completely unemployable. Two years later delusions of grandeur began to appear during the excited phases. Three years later still her general habits began to deteriorate, and they continued to do so progressively for the next six years without remission.

Leucotomy was performed about fifteen years after the onset of illness. Subsequent investigation revealed the lesions to lie in planes " $\mathrm{A} / \mathrm{M}$ " and " $\mathrm{M}$ " and to involve all except the dorsal segment of white matter and the medial orbital region on each side (Fig. 8).

Postoperative History.-For two and a half months after the operation she was well behaved, displayed a sense of humour and willingness to work for the first time since admission, was clean in her habits, and took an interest in her personal appearance. For no apparent reason she then suddenly relapsed to her pre-operative deteriorated psychotic state and remained so until her death from chronic phthisis one year and nine months after the operation. The remission was brief, but very striking when contrasted' with her pre-operative history.

\section{Discussion}

Clinical Features.-Most writers have not given any clinical detail of their relapsed leucotomy cases, but Cook (1946) has described two patients with agitated depression who relapsed after one and a half years, and two with " somatopsychic" delusions who relapsed after four to five months ; Frank (1946) referred to two paraphrenics who relapsed after one year and one aggressive psychopath who relapsed eight months after operation; and Garmany (1948) has reported an acutely obsessional patient with full relapse after complete postoperative recovery over a period of four years, and a catatonic who relapsed after three years of mental health. The types of mental symptoms and syndromes in these patients who suffered relapse and in the six under review comprise, therefore, most of the commonest components of the functional psychoses. Each symptom can apparently relapse to a degree of severity at least equal to its pre-operative intensity, "tension," the most generally agreed prognostic criterion for the operation, being no exception.

What is perhaps of more theoretical than practical importance is that in all the foregoing cases the symptoms that recurred were of the same kind as those present before operation. The only exceptions to this known to the writers are several cases of typical catatonic schizophrenia which Dr. L. C. Cook (personal communication) has observed to change after leucotomy into typical hebephrenic schizophrenia, and two instances in the writers' experience where a patient with an early-treated affective condition displayed, on relapse from moderate postoperative improvement, prominently schizophrenic features which had been present, but overshadowed, in the previous clinical picture.

A more practical consideration is that in Case the circumstances of unsuccessful search for congenial job and complications in love affaif seemed to play a determining part in the relapse likewise the carbuncle in Case 2 and the,jilting episode in Case 4. Frank attributed the relapse in one of his paraphrenics to harassing circumstances Cameron and Prados (1948) likewise related the relapse, in five out of seven neurotic patients treate $\bar{\phi}$ by gyrectomy, to the amount of stress after dise charge. Hence environmental factors would seen able to play just as determining or precipitating role in the ætiology of relapse after leucotomy a they can at the onset of illness. That they may indeed have stronger influence than before operation. would seem suggested by the facts that in Case $P$ and Case 4 of the present series the patient responde $\vec{d}$ more favourably to psychological methods of treatment after relapse than before the leucotomy the improvement in the paranoid state of anothep patient, not described here, was after operation s $\vec{\phi}$ well maintained by E.C.T. that his case could be classified as one of aborted relapse; Liebert a d Davis (1948) report one patient whom E.C. T restored to normal mood only after postoperate relapse ; and Fernandes and his associates (1948) mention four cases in which E.C.T., and one if which insulin therapy, became effective for the time after relapse. It would appear, therefore, that there may be some general postoperative increase responsiveness to the environment which mighto allow considerable scope for prevention of relapse in at least a proportion of cases.

An additional point of interest in Case 1 is that the lesions " isolated" very nearly the same areas of cortex as Heath and Pool (1948), Mettler an $\$$ others (1948), and Le Beau and others (1948a and b) have been ablating and which Freeman (1948 considers his transorbital leucotomy to isolate namely dorsal areas 10 and 46 and anterior area of Brodmann. The clinical status of the case falls within Freeman's criteria for good results after such rostral circumscribed cuts. It cannot of course be judged whether the illness might not have remitted spontaneously about the date of the leucotomyo This is a difficulty in evaluation which must bese all such early operative cases until large numbers with fair controls, are available for statisticat scrutiny. Another noteworthy feature of this cas is that the personality change was of the euphori․․․ type and not the akinetic (apathetic) type that would be expected by supporters of Kleist's (1937) concept of localization of functions within the granulap frontal cortex. A further point of note is the 
absence of appreciable deterioration in any component (as defined by Hutton and Basset, 1948) of the patient's artistic ability. This finding seems hardly consistent with Freeman and Watts's (1948) concept of localization of creative artistry in the polar regions, though it must be conceded that not the whole of the polar cortex was isolated in the present case.

Anatomical Features.-Four of the present cases (Nos. 3, 4, 5, and 6) can reasonably be described as having suffered practically complete bilateral isolation of the prefrontal cortex from its long fibre connections, gyrus rectus and posterior area 9 being the only regions consistently spared. The symptoms concerned in these four cases are fairly varied. Bilateral " isolation," therefore, of practically the whole prefrontal cortex does not prevent the remanifestation, after their relatively prolonged disappearance or striking amelioration, of many of the commonest psychotic symptoms. Hence, either the " isolated" cortex can in course of time become effectively reactivated through relays of subcortical U fibres, or through largely intracortical pathways, and can redetermine abnormal behaviour, or else psychopathological symptoms can develop anew without participation of the prefrontal regions.

That the former possibility may be the case is strongly suggested by the fact that degenerative nerve cell changes do not occur to any appreciable degree in the cortex rostral to the lesions (Freeman and Watts, 1942; Meyer and Beck, 1945). According to the theories associated with transneuronal degeneration this would imply that these nerve cells continue to derive stimuli from elsewhere than the cut corticopetal projection and association fibres. Again, and in full corroboration of the foregoing, the electro-encephalographic recordings from the prefrontal regions after leucotomy return to a relatively normal pattern after a period of from three weeks to three months (Cohn, 1945 ; Greville and Last, 1947), a duration which according to our experience coincides closely with the period of active absorption of blood and necrotic tissue within the scars.

That a patient completely deprived of his prefrontal regions may continue uninterruptedly to manifest at least some forms of psychopathological behaviour is demonstrated by instances of bilateral prefrontal lobectomy where the psychosis has persisted. Two such cases (both chronic deteriorated hebephrenic schizophrenias) have been reported by Peyton and his co-workers (1948) and Cook (personal communication) has one such patient, a chronic deteriorated catatonic, who has shown no improvement whatever. Again, there were, among those patients whose brains have been investigated at the Maudsley Laboratory, three suffering from chronic deteriorated catatonic schizophrenia in whom not even transient improvement followed full 9- to 10-segment cuts. It may not be without significance that all six of these patients were deteriorated schizophrenics.

Actual relapse from normality after apparently. successful lobectomy has not yet been reported in the literature. In a personal communication, however, Drs. W. T. Peyton and E. W. Miller state that, of their series of fourteen lobectomy cases reported with Noran in February, 1948, they now (January, 1949) consider that one chronic catatonic schizophrenic patient (No. 10) who had improved appreciably after lobectomy started to regress about one year later into a state of severely deteriorated hebephrenia, and that the patient with chronic puerperal psychosis (No. 11) who had shown " marked improvement" regressed almost completely to her pre-operative state three months after the operation. It is doubtful whether the ultimate relapse of five out of the seven neurotic cases: subjected to gyrectomy by Cameron and Prados should be taken as evidence that many conditions other than chronic deteriorated schizophrenia and puerperal psychosis could develop again in patients deprived of the bulk of their prefrontal cortex. It may be that in these five cases the small amount of cortex removed relative to the severity of the neurosis was the main factor responsible for the impermanency of the clinical improvement (compare McLardy and Meyer, in the press).

The above observations give no information as to whether such mental symptoms can appear for the first time after loss of the prefrontal regions. They therefore neither support nor contradict -at least one interpretation of Freeman and Watts's (1942) thesis that "without the frontal lobes there could be no functional psychoses." Many of the foregoing facts are, however, manifestly inconsistent with such a rigid theory of relationship of structure to mental function as propounded by Kleist and doubtfully compatible with Freeman and Watts's (1948) more dynamic concept that " a neurosis or psychosis actually begins with a certain fixation of ideational activities and their underlying neural substrates in the tip of the frontal lobe," energized largely through the dorsomedial nucleus of the thalamus. The facts call for some more plastic concept of brain function such as has been advocated by Lashley (1941) and Golla $(1943,1946)$ : plasticity in recovery of abnormal as well as normal function.

\section{Summary}

Six patients are described in whom mental illness 
recurred some considerable time after apparently successful leucotomy and in whom the precise extent of the brain lesions was subsequently determined in the laboratory. Anatomical features of the six cases are discussed, together with those of other "psychosurgical" cases in the literature in which the extent of the lesions was determinable during life. Clinical features of the six cases are reviewed together with those of other relapsed cases in the literature of "psychosurgery" in which diagnostic details are available. The following conclusions are come to :

1. Many of the symptoms and syndromes characteristic of affective and schizophrenic-functional psychoses can recur after practically complete isolation of the prefrontal cortex from its long fibre connexions. Some chronic schizophrenic symptoms, at least, can not only persist but can disappear and then recur after full bilateral prefrontal lobectomy. Many neurotic symptoms can recur after disappearance following removal of more limited amounts of prefrontal cortex.

2. The illness which recurs is practically always of the same type as the pre-operative one.

3. There are indications that the power of environmental influences for both good and ill may be augmented after the operation.

4. Case 1 also touches on the problem of localization in the prefrontal regions in relation to type of personality change and to creative ability.

5. The facts demand a generous conception of the degree of plasticity within both the abnormally and the normally functioning brain.
The writers wish to express their thanks to Professo Alfred Meyer for his help throughout the preparatich of the paper, to Professor Aubrey Lewis for his criticismฐ, to Miss M. A. Lane for her investigations of the socia factors in Case 1, and to the Medical Superintendents by whose courtesy the clinical and pathological materia] was made available.

\section{REFERENCES}

Cameron, D. E., and Prados, M. D. (1948). Ass. R nerv. ment. Dis., $27,534$.

Cohn, R. (1945). Arch. Neurol. Psychiat., Chicago, 5 283.

Cook, L. C. (1946). Proc. R. Soc. Med., 39, 449.

Fernandes, B., Polonio, P., Gomes, S., and others (1948) Abstract in Digest Neurol. Psychiat., 16, 684.

Frank, J. (1946). Proc. $R$. Soc. Med., 39, 455.

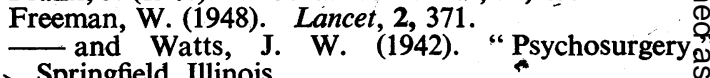

- Springfield, Illinois.

Freeman, W., and Watts, J. W. (1948). Digest Neurof Psychiat., 16, 62.

Garmany, G. (1948). J. ment. Sci., 94, 428.

Golla, F. L. (1943). Ibid., 89, 189.

-(1946). Proc. R. Soc. Med. 39, 443.

Greville, G. D., and Last, S. L. (1947). Ibid., 40, 145.

Heath, R. G., and Pool, J. L. (1948). J. Nerv. ment Dis., 107, 411.

Hutton, E. L., and Bassett, M. (1948). J. ment. Sfíco 94, 332.

Kleist, K. (1937). Z. ges. Neurol. Psychiat., 158, 158.

Lashley, K. S. (1941). Proc. Amer. phil. Soc., 84, 46\$.

Le Beau, J. (1948). Sem. Hop. Paris, 24, 1937. 80, 481 .

Liebert, E. and Davis, L. (1948). Illinois med J 203.

McLardy, T., and Meyer, A. "Anatomical Correte of Improvement after Leucotomy." (In the presi잉 $\overrightarrow{0}$

Mettler, F. A., Pool, J. L., Heath, R. G., Landis, C., ?n others. (1948). Digest Neurol. Psychiat., 16, 756.

Meyer, A., and Beck, E. (1945). J. ment. Sci., 91, 41D

Peyton, W. T., Noran, H. H., and Miller, F. W. (1948 Amer. J. Psychiat., 104, 513. 